\title{
Relationships Between Physical Activity Levels, Self-Identity, Body Dissatisfaction and Motivation Among Spanish High School Students
}

\author{
by \\ Pedro Antonio Sánchez-Miguel ${ }^{1}$, Francisco Miguel Leo ${ }^{1}$, \\ Diana Amado², Juan José Pulido², David Sánchez-Oliva²
}

The aim of this study was to examine the relationships between gender and the educational grade on the one hand, and physical activity levels, motivation, self-identity, body dissatisfaction, the intention to be physically active and daily sitting time on the other, in a sample of Spanish high school adolescents. The sample consisted of 2087 Spanish students from the $3 \mathrm{rd}(n=1141)$ and 4 th grade $(n=946)$, both male $(n=1046)$ and female $(n=1041)$, ranging in age from 15 to 17 years old $(M=15.42 ; S D=.86)$. Students completed questionnaires to assess their levels of physical activity, self-identity, motivation, intention to be physically active and daily sitting time. The students' perceptions of their body height and mass were also tested. With the exception of walking MET values, the results showed gender differences in the variables tested. Male participants showed higher intrinsic motivation and lower amotivation than female participants. Furthermore, male students revealed higher levels of physical activity than female students. Finally, the research concluded with the importance of promoting intrinsic reasons for physical activity in order to encourage positive consequences in high school students.

Key words: motivation, students, physical activity, body image.

\section{Introduction}

Despite widespread knowledge of the negative consequences of physical inactivity (PI) over the short, medium and long term, this phenomenon is increasing in the general population (Ogden et al., 2010). The tendency towards PI is considered one of the most serious health problems of the 21st century. It is also known as sedentary behaviour, operationally defined as behaviour that predominantly involves sitting, and it can have deleterious health consequences (Biddle et al., 2010). It is important to note that promoting non-sedentary behaviour in children and adolescents can prevent or solve other health issues in the future (Tremblay et al., 2011a) that represent a major public health problem in developed countries and directly influence life expectancy (Lee et al., 2012). In this regard, encouraging children to be physically active is an important public health objective and disease prevention strategy (Jansen and LeBlanc, 2010; Strong et al., 2005; Tremblay et al., 2011b).

Determining the correlates of participation in physical activity (PA) and sport is an initial step that may help to target at-risk populations and guide the development of relevant health promotion programmes, especially for adolescents (Taliaferro et al., 2010). There are many factors related to adolescents' overall PA levels such as body mass index (BMI), self-identity, daily sitting time, social context, motivation and income levels (Sánchez-Oliva et al., 2014; Wilcox et al., 2003). Hence, the factors

1 - Teacher Training College, University of Extremadura.

2 - Faculty of Sports Sciences, University of Extremadura. 
associated with PA levels have been of interest to many authors (Wilcox et al., 2003). This study aimed to investigate the relationship between some of the most relevant factors related to adolescents' PA levels, based on gender and the education level, as it has been shown that regardless of age, boys are more active than girls (Azevedo et al., 2007).

According to the measurement of PA in educational settings, the use of direct methods (e.g. GPS, accelerometers and calometric methods) is not possible with large populations (Biernat and Stupnicki, 2005), and normally, questionnaires are used to self-report PA due to their cost effectiveness, ease of administration, ability to determine discrete categories of PA, ability to provide details about PA and ability to show improvements across groups or individuals (Sylvia et al., 2014). Among the available questionnaires, the International Physical Activity Questionnaire (IPAQ) stands out due to its recommendation from the European Health Interview Society (EUROHIS) and the European Physical Activity Surveillance System (EUPASS) to be applied to individuals aged between 15 and 69. There are also specific variables that might influence or correlate with PA. One of the most important variables is the BMI, which is determined by body height and mass and reported in units of kilogram/metre squared $(\mathrm{kg} / \mathrm{m} 2)$. However, body height and mass are sometimes difficult to assess in children and adolescents in large populations, thus a selfreported BMI is often used (Brener et al., 2003; Crawley and Portides, 1995). A high BMI is associated with low levels of PA (Rauner et al., 2013).

Participation in PA is known as one of the best methods to achieve the ideal body image (BI). BI relates to an individual's perception of their body related to their body size and shape (Grogan, 2008). Moreover, it has been suggested that PA may be beneficial for BI and that there is a significant relationship between $\mathrm{PA}$ and $\mathrm{BI}$ (Altintas et al., 2014). BI issues may influence individuals' health-related behaviour, and therefore contribute to predictions of levels of PA in both genders (Finne et al., 2011). Recently, there has been increasing research into the relationship between PA and motivation (Teixeira et al., 2012). This relationship is often related to multiple engagement techniques and different types of regulation in PA and sport (Deci and Ryan, 2000). Therefore, as long as this relationship is understood, a prediction concerning future PA and sporting practice might be possible (IsoAhola and St. Clair, 2000; Maszczyk et al., 2012). Therefore, a rigorous examination of how different types of motivation (both intrinsic (IM) and extrinsic (EM)) are associated with PA and commitment to sport is imperative for sustaining an interest in PA and sport (Teo et al., 2015). Teixeira et al. (2012) concluded that a motivational profile marked by IM was important for sustaining exercise behaviours over time.

Regarding gender differences in motivation towards PA, Sarrazin et al. (2002) studied 335 French handball players and revealed that female athletes were more IM-oriented, showing a greater interest in fun, satisfaction and pleasure than male athletes. In a study of 172 US collegiate athletes, Kingston et al. (2006) found that male athletes with sports scholarships demonstrated significantly higher levels of EM than female athletes. Regarding gender differences in PA levels, Azevedo et al. (2007) showed that men presented higher activity levels than women in terms of moderate-intensity, vigorous-intensity and total leisure-time PA in all age groups. In a study conducted with 395 adolescents from Chile, Garcia-Hermoso and Marina (2017) found that male participants were more active than girls. PA declines with age (Sallis, 2000), and motivation is highlighted as one of the main factors in the decrease in PA (Gillet et al., 2012).

In addition to the direct health benefits of PA, the documented health benefits include the improvement of well-being (Rodhes et al., 2016), the development of which self-identity is crucial to, as well as a range of adaptive behavioural, educational, cognitive and social outcomes (Craven and Marsh, 2008). Many studies have shown the importance of PA in maintaining and improving self-identity (Lee et al., 2012; Paluska and Schwenk, 2000). Moreno et al. (2007) indicated that boys had higher levels of perceived competence and greater self-confidence than girls in relation to sporting activities, whereas girls had a more favourable perception of their physical appearance and physical strength than boys.

Finally, with respect to levels of PA, daily 
sitting time is another factor to take into account. Carson et al. (2015) found that girls had higher totals for daily sitting time and participated in less moderate and vigorous PA (MVPA) than males across most demographic groups in the US. However, to our knowledge, no study has examined the relationships between levels of PA, perception of the BMI, body dissatisfaction, motivation, self-identity, daily sitting time and differences between genders in a large sample of adolescents. As it was previously shown, only a few studies have focused on gender differences in some of the variables related to PA levels, or tested differences between educational levels. Hence, the importance of this research derives from the use of different variables related to PA, emphasizing motivation and showing the differences between the genders and educational level.

The aim of this study was to examine the relationships between gender and the educational level in variables related to PA levels, as well as gender and educational level differences in PA levels, motivation, self-identity, body dissatisfaction, the intention to be physically active and daily sitting time, in a sample of Spanish high school adolescents. In line with this aim, the first hypothesis was that there were significant differences between males and females in their levels of PA, the intention to be physically active, the perception of the BMI, body dissatisfaction, motivation, self-identity and daily sitting time. Girls would record lower scores than boys in all variables except amotivation. The second hypothesis of the study was that students in older age groups would record lower levels of IM and self-identity than students in younger age groups.

\section{Methods}

\section{Participants}

The sample consisted of 2087 Spanish students from the $3^{\text {rd }}(\mathrm{n}=1144)$ and $4^{\text {th }}$ grade $(\mathrm{n}=$ $946)$, both male $(n=1046)$ and female $(\mathrm{n}=1041)$, ranging in age from 15 to 17 years old $(M=15.42$; $S D=.86)$ from different high schools in Extremadura (Spain). They were recruited from 17 public schools located in western Spain that belonged to a health education programme.

\section{Measures}

Self-perception and body size satisfaction.
The Stunkard Figure Rating Scale (Figure 1) was used to assess self-perception and ideal body sizes. The Stunkard scale consists of nine silhouette figures that range from 1 (very thin) to 9 (very obese) (Stunkard et al., 1983). Self body size is the number of the figure selected by participants in response to the prompt "Choose the figure that reflects how you think you look". Ideal body size is the number of the figure chosen in response to the prompt "Choose your ideal figure". Thus, the body size satisfaction variable is defined as the difference between one's perceived self body size and perceived ideal body size.

Perception of body height and mass.

To measure the perception of body height and mass in adolescents, questions asking for their body height (e.g. "Do you know how tall you are?") and mass (e.g. "Do you know how much you weigh?") were used. Individuals answered with their perception of their body height $(\mathrm{cm})$ and mass $(\mathrm{kg})$, and the perception of their BMI was calculated.

Self-identity.

To examine adolescents' self-identity, a Spanish version (PSPP: Moreno et al., 2007) of the Physical Self-Perception Profile (Fox, 1990; Fox and Corbin, 1989) was used. This instrument consists of 28 items that test five factors: fitness (six items, such as "I feel very confident to continually exercise and maintain my fitness"), appearance (six items, such as "I am very satisfied with how I am physically"), perceived competence (five items, such as "I am very good at almost every sport"), physical strength (five items, such as "I think that I am not as good as many others when I deal with situations in which strength is required") and selfesteem (six items, such as "I feel a little uncomfortable in places where physical exercise and sports are practiced"). Items were rated on a five-point Likert scale ( 1 = "strongly disagree", 5 = "strongly agree"). The instrument showed acceptable internal consistency, as all factors had a Cronbach's alpha value of over 0.70 apart from physical strength, which at 0.63 is still considered acceptable (Lowenthal, 2001). Values slightly lower than 0.70 may be accepted if the number of items that make up the factor is not particularly high (Hair et al., 1998).

Motivation toward PA during leisure time.

IM and amotivation were measured using the Spanish adaptation (González-Cutre et al., 2010) 
of the Behavioural Regulation in Exercise Questionnaire (BREQ-3; Wilson et al., 2006). Each factor contained four items that followed the statement "I exercise because...": IM (e.g., "because I feel pleasure and satisfaction when I exercise"), and amotivation (e.g., "I think I am wasting my time with exercise"). In these two scales, items were rated on a five-point Likert scale ( 1 = "strongly disagree", 5 = "strongly agree"). The Cronbach's alpha values were 0.84 for IM and 0.78 for amotivation.

Levels of $P A$.

To assess the levels of PA in adolescents, the International Physical Activity Questionnaire (IPAQ) was used. This is an international method of self-administration created to provide an estimate of and practical information about PA. IPAQ (Craig et al., 2003) is an instrument that was developed for cross-national monitoring of PA and PI.

Daily sitting time.

An item was included to assess students' daily sitting time: "How many hours do you watch TV or play computer or video games?". Participants responded using a five-point Likert scale ranging from 0 ( 0 hours) to 5 (more than 5 five hours per day). Previous research had implemented single-item scales effectively (Ntoumanis, 2001; Shen, 2014).

Intention to be physically active.

One item was included to measure students' intention to participate in PA outside of the school curriculum: "In the coming years, I intend to participate in sport/physical activity". The questionnaire specified that "sport participation" referred to participating in PA or a sport on a regular basis (at least twice a week). Participants responded using a five-point Likert scale ranging from 1 (strongly disagree) to 5 (strongly agree). Previous research had implemented single-item scales effectively (Ntoumanis, 2001; Shen, 2014).

\section{Procedures}

The study was approved by the Ethics Committee of the University of Extremadura. All participants were treated according to the American Psychological Association (2009) ethics guidelines regarding consent, confidentiality and the anonymity of responses. Informed consent was provided by teachers and fathers or mothers, explaining all the variables to assess and taking into account that the adolescents included in the study were minors. Individuals filled in a questionnaire using a coding system to protect confidentiality. Participants completed the questionnaire in a classroom before a physical education class. They completed the questionnaire in 15-20 $\mathrm{min}$, in the absence of a teacher, supervised by the research assistants and under non-distracting conditions.

\section{Data analysis}

SPSS 21.0 was used to examine the data. Firstly, a reliability analysis (Cronbach's alpha coefficient) and a bivariate correlation analysis using Pearson's bivariate correlation coefficients were conducted. Secondly, two analyses of variance were performed, taking into account the independent variables of gender and the educational level of participants.

\section{Results}

\section{Bivariate correlations}

Table 1 shows the correlations obtained between all the variables included in the study. Firstly, Metabolic Equivalent of Task (MET) value for walking was positively associated $(p<.01)$ with the MET value for moderate PA (.16) and totals (.07). Moreover, daily sitting time was significantly associated $(p<.01)$ with moderate PA $(-0.13)$ and vigorous PA (-.11), fitness (-.12), perceived competence (-.10), self-esteem (-.10), appearance (-.21) and IM (-.06). Moderate and vigorous PA MET values were significantly correlated $(p<.01)$ with fitness (.24 and .28$)$, perceived competence (.19 and .23) and IM (.17 and .19 , respectively).

On the other hand, IM was positively associated $(p>.01)$ with all the factors in the Spanish version of the PSPP (Moreno et al., 2007) with the exception of the intention to be physically active, body dissatisfaction and selfesteem $(p>.05)$. Moreover, amotivation was very negatively associated $(p<.01)$ with vigorous PA and total MET values, perception of fitness, appearance and perception of competence. According to the factors of the PSPP, the relationships were positive $(p<.01)$ between fitness, perceived competence and strength, and there were negative relationships $(p<.01)$ between strength, self-esteem and appearance. Furthermore, there was a negative relationship ( $p$ $>$.01) between IM and amotivation (-.66). Lastly, it 
is important to note the positive relationship $(p<$ .01) between the perception of the BMI and low levels of PA and self-identity, and the positive relationship $(p<.01)$ between low levels of PA and low scores in self-identity.

Analysis of differences between gender

Independent sample t-tests were developed with the aim of examining the differences between male and female students (Table 2). Several differences can be seen. First, regarding MET values, daily sitting time and the intention to be physically active, male students had higher MET values in moderate and vigorous PA and in total (all $p<.001$ ) than female students. However, there were differences between male and female students in their walking MET values. Here, female students had higher daily sitting time than male students $(p<.001)$. Male students had more intention to be physically active than female students $(p<.001)$.

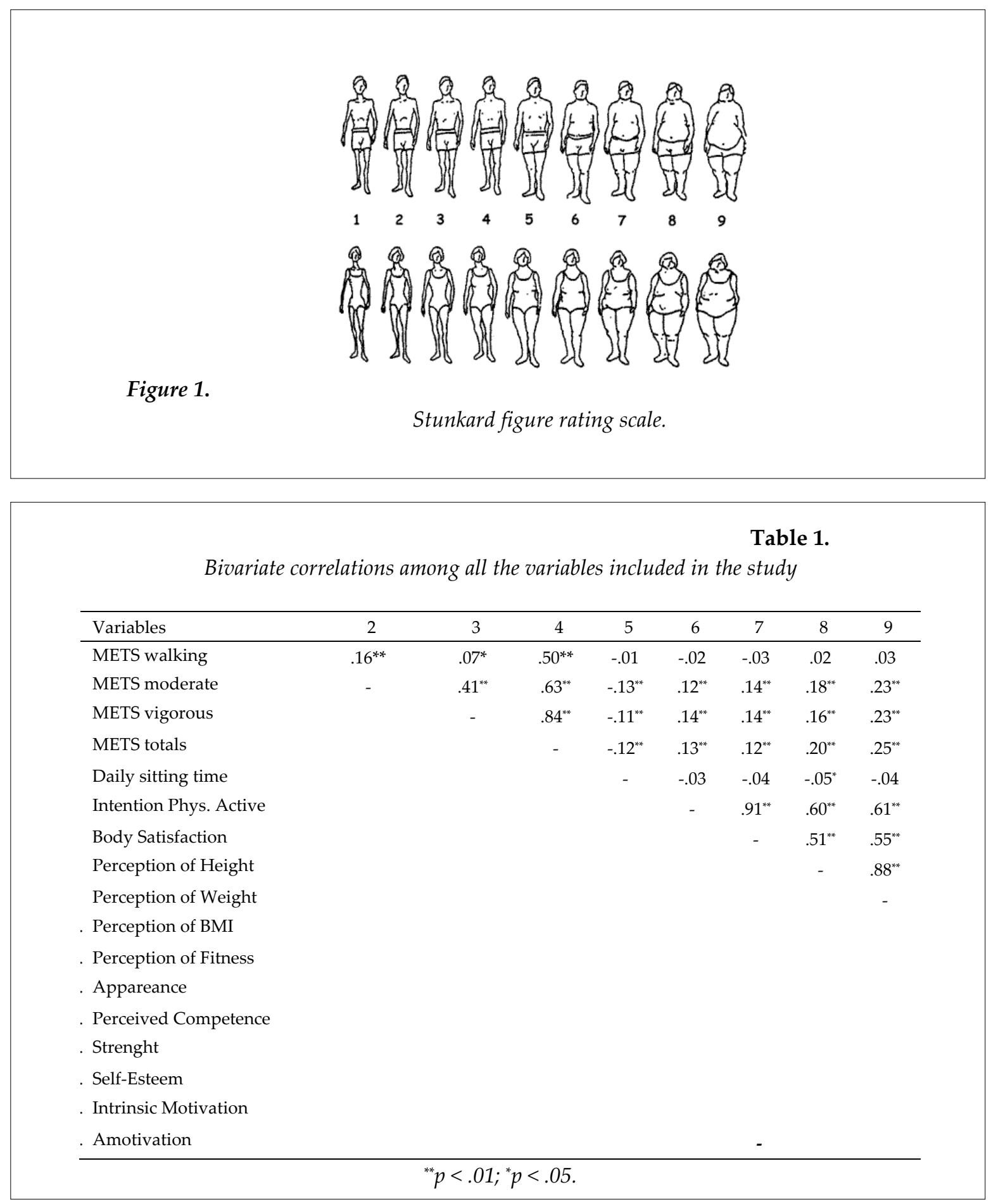


Table 1. (Continued).

Bivariate correlations among all the variables included in the study

\begin{tabular}{lcccccccc}
\hline Variables & 10 & 11 & 12 & 13 & 14 & 15 & 16 & 17 \\
\hline METS walking & -.06 & $.07^{*}$ & .04 & .02 & $.06^{* *}$ & .04 & .04 & $.06^{*}$ \\
METS moderate & .03 & $.24^{* *}$ & $.23^{* *}$ & $.19^{* *}$ & .02 & -.01 & $.17^{* *}$ & $-.05^{*}$ \\
3. METS vigorous & .03 & $.28^{* *}$ & $.29^{* *}$ & $.23^{* *}$ & .05 & .01 & $.19^{* *}$ & $-.08^{* *}$ \\
4. METS totals & -.00 & $.33^{* *}$ & $.32^{* *}$ & $.27^{* *}$ & .04 & .00 & $.25^{* *}$ & $-.16^{* *}$ \\
5. Daily sitting time & -.03 & $-.10^{* *}$ & $-.10^{* *}$ & -.04 & $-.21^{* *}$ & $-.06^{* *}$ & $-.08^{* *}$ & -.02 \\
6. Intention Phys. Active & $.72^{* *}$ & -.02 & $.04^{*}$ & $.30^{* *}$ & -.03 & .01 & .00 & .02 \\
7. Body Satisfaction & $.86^{* *}$ & -.06 & .00 & $.32^{* *}$ & $-.07^{*}$ & $-.15^{* *}$ & -.00 & .04 \\
8. Perception of Height & $.08^{* *}$ & $.20^{* * *}$ & $.24^{* *}$ & $.30^{* *}$ & -.03 & $-.04^{*}$ & $.13^{* *}$ & $-.06^{* *}$ \\
9. Perception of Weight & $.07^{* *}$ & $.19^{* *}$ & $.26^{* *}$ & $.32^{* *}$ & $.11^{* *}$ & .05 & $.15^{* *}$ & -.03 \\
10. Perception of BMI & - & $-.18^{* *}$ & $-.14^{* *}$ & $.19^{* *}$ & $-.16^{* *}$ & $-.22^{* *}$ & $-.10^{* *}$ & $.07^{*}$ \\
11. Perception of Fitness & & - & $.75^{* *}$ & $.50^{* *}$ & $-.08^{* *}$ & $-.07^{* *}$ & $.59^{* *}$ & $-.34^{* *}$ \\
12. Appareance & & & - & $.53^{* *}$ & $-.09^{* *}$ & $-.05^{*}$ & $.57^{* *}$ & $-.31^{* *}$ \\
13. Perceived Competence & & & & - & $-.06^{* *}$ & $-.04^{* *}$ & $.31^{* *}$ & $-.14^{* *}$ \\
14. Strenght & & & & & - & $.59^{* *}$ & $-.08^{* *}$ & .04 \\
15. Self-Esteem & & & & & & - & -.03 & -.00 \\
16. Intrinsic Motivation & & & & & & & - & $-.66^{* *}$ \\
17. Amotivation & & & & & & & & - \\
\hline
\end{tabular}

${ }^{* *} p<.01 ;{ }^{*} p<.05$.

Table 2.

Differences between gender in all the variables included in the study

\begin{tabular}{|c|c|c|c|}
\hline & Male $(n=498)$ & Female $(n=280)$ & \\
\hline & $M(S D)$ & $M(S D)$ & $t$ \\
\hline METS walking & $1383.92(1707.09)$ & $1292.44(1413.94)$ & 1.12 \\
\hline METS moderate & $1440.97(1347.52)$ & $859.86(792.65)$ & $9.06^{* * *}$ \\
\hline METS vigorous & $3409.99(3042.79)$ & $2038.72(2016.32)$ & $9.27^{* * *}$ \\
\hline METS totals & $4953.18(4128.09)$ & $2837.80(2817.42)$ & $12.78^{* * *}$ \\
\hline Daily sitting time & $424.25(181.85)$ & $482.68(182.76)$ & $-6.07^{* * *}$ \\
\hline Intention physically active & $4.50(.90)$ & $4.16(1.00)$ & $8.11^{* * *}$ \\
\hline Body satisfaction & $.23(1.04)$ & $.64(.90)$ & $-9.76^{* * *}$ \\
\hline Perception of height & $170.67(8.46)$ & $161.99(6.47)$ & $25.78^{* * *}$ \\
\hline Perception of weight & $60.79(10.59)$ & $53.16(8.18)$ & $18.05^{* * *}$ \\
\hline Perception of BMI & $20.81(3.02)$ & $20.24(2.81)$ & $4.36^{* * *}$ \\
\hline Perception of Fitness & $3.67(.86)$ & $3.05(.85)$ & $20.57^{* * *}$ \\
\hline Perception of Competence & $3.55(.89)$ & $2.72(.94)$ & $16.01^{* * *}$ \\
\hline Perception of Strength & $3.27(.81)$ & $2.67(.75)$ & $16.01^{* * *}$ \\
\hline Perception of Self-Esteem & $2.89(1.04)$ & $2.82(.92)$ & $1.59^{* *}$ \\
\hline Perception of Appearance & $3.09(.78)$ & $2.88(.83)$ & $5.69^{* * *}$ \\
\hline Instrinsic motivation & $4.26(.91)$ & $3.75(.96)$ & $12.25^{* * *}$ \\
\hline Amotivation & $1.49(.81)$ & $1.63(.87)$ & $-3.93^{* * *}$ \\
\hline
\end{tabular}

${ }^{*} p<.05,{ }^{* * *} p<.01,{ }^{* * * *} p<.001$. 


\begin{tabular}{|c|c|c|c|}
\hline \multicolumn{4}{|c|}{$\begin{array}{c}\text { Table } 3 . \\
\text { Differences between educational levels in all the variables included in the study }\end{array}$} \\
\hline & $3^{\mathrm{o}}$ & $4^{\circ}$ & \\
\hline & $M(S D)$ & $M(S D)$ & $t$ \\
\hline METS walking & $1351.29(1597.26)$ & $1321.47(1529.16)$ & .36 \\
\hline METS moderate & $1206.67(1172.13)$ & 1161.29 (1176.23) & .69 \\
\hline METS vigorous & $2767.72(2425.35)$ & $2895.58(3069.84)$ & -.84 \\
\hline METS totals & $3908.12(3557.67)$ & $3917.10(3859.73)$ & -.05 \\
\hline Daily sitting time & $451.06(197.89)$ & $454.05(179.44)$ & -.31 \\
\hline Intention physically active & $4.32(.99)$ & $4.35(.94)$ & -.76 \\
\hline Body satisfaction & $.46(.99)$ & $.40(.99)$ & 1.37 \\
\hline Perception of body height & $55.71(8.67)$ & $58.56(8.61)$ & $-6.29^{* * *}$ \\
\hline Perception of body mass & $165.47(10.34)$ & $167.43(9.84)$ & $-5.05^{* * *}$ \\
\hline Perception of BMI & $20.26(3.00)$ & $20.84(2.81)$ & $-4.47^{* * *}$ \\
\hline Fitness & $3.44(.90)$ & $3.28(.92)$ & $4.06^{* * *}$ \\
\hline Competence & $3.20(.99)$ & $3.07(1.02)$ & $3.06^{* *}$ \\
\hline Strength & $3.03(.84)$ & $2.91(.83)$ & $3.10^{* *}$ \\
\hline Self-Esteem & $2.88(.99)$ & $2.85(.98)$ & .64 \\
\hline Appearance & $3.03(.83)$ & $2.95(.80)$ & $2.15^{*}$ \\
\hline Instrinsic motivation & $4.06(.97)$ & $3.94(.97)$ & $2.67^{* *}$ \\
\hline Amotivation & $1.54(.85)$ & $1.58(.85)$ & $-1 . .18$ \\
\hline \multicolumn{4}{|c|}{${ }^{*} p<.05,{ }^{* *} p<.01,{ }^{* * *} p<.001$} \\
\hline
\end{tabular}

Secondly, regarding body satisfaction and perception of body height, mass and BMI, male students had better perception of body height, mass and BMI as well as greater perception of body satisfaction than female students (all $p<$ .001). Thirdly, regarding self-identity and motivation, male students had better perception of self-identity (fitness, competence, strength, selfesteem, appearance) and IM $(p<.001)$ than female students. Only amotivation was significant higher in female students than male students $(p<.001)$.

\section{Analysis of differences between educational level}

In order to find out the differences in educational levels, a t-test was conducted (Table 3). As can be seen in the table, there are various differences. Firstly, regarding the perception of the BMI, results showed greater values $(p<.001)$ in the students belonging to the $4^{\text {th }}$ grade. Secondly, there are differences $(p<.001)$ in the perception of fitness, competence and strength, revealing higher values for students from the $3^{\text {rd }}$ than students from the $4^{\text {th }}$ grade. Finally, it is important to note that students from the $3^{\text {rd }}$ grade showed higher values of IM $(p<.001)$ than students from the $4^{\text {th }}$ grade.

\section{Discussion}

This study aimed to examine the possible relationships between variables related to PA levels, as well as gender and educational grade differences in PA levels, motivation, self-identity, body dissatisfaction and daily sitting time in a sample of Spanish high school adolescents. According to the aims, the first hypothesis was that there were significant differences between males and females in levels of PA, perception of the BMI, body dissatisfaction, motivation, selfidentity and daily sitting time.

The results showed gender differences in most of the variables included in the research. Regarding levels of PA, the outcomes revealed significant differences in moderate, vigorous and total levels of PA, with higher scores for male than female students. Only in walking MET values did not show significant differences. These results are consistent with those of Dagmar et al. (2001), who found higher scores for PA in males than females, explained mainly by differences in 
vigorous PA. Furthermore, these outcomes might be explained by the fact that adolescent males spend more time participating in moderate and vigorous PA than girls at the same age (Van Mechelen et al., 2000). Therefore, the intention to be physically active is higher in men than women, probably because women associate their leisure time with social activities, rather than PA or sporting behaviour (Tessier et al., 2007). Women spend more time at rest each day (Carson et al., 2015), which was confirmed in this study.

Also, the results revealed that there were significant differences between adolescent males and females with regard to their perceptions of the BMI. However, body dissatisfaction was higher in young women than men. This might be due to the fact that if female students are dissatisfied with their body, they also have lower levels of self-identity (e.g. fitness, perception of competence, strength), which may be a result of their low levels of PA (Duncan et al., 2011). Finally, females recorded higher levels of amotivation and lower levels of IM than boys, results which are not consistent with previous research (Kingston et al., 2006; Sarrazin et al., 2002). This is probably due to the fact that this was in an educational context, and not a sporting performance context. These low levels of IM in girls might predict an intention to be physically active in the future, as has been shown in other research (Sánchez-Oliva et al., 2014). Therefore, according to the results, the first hypothesis was confirmed.

The second hypothesis was that students at higher levels of education would record lower levels of IM and self-identity. The results revealed a lower perception of fitness, perception of competence and IM at higher levels of education ( $4^{\text {th }}$ grade) than at lower levels ( $3^{\text {rd }}$ grade). These results might be a logical effect of lower levels of PA as students get older (Sallis, 2000), which might also be a determiner of low levels of physical self-identity and low levels of fun, pleasure and interest in the activity itself (Duncan et al., 2011). Moreover, these results are in line with other researchers (Gillet et al., 2011) who found that motivation varied with age and depended on several factors, one of the most important being social support (from teachers, parents, etc.). Hence, the second hypothesis was also confirmed.

The strength of this study is that it consisted of a large number of participants with which results could be generalized. Thus, two further implications for practice arose from this study: firstly, the necessity to promote motivational programmes for students to improve their levels of PA and self-identity, and secondly, the importance of IM in order to maintain positive behaviors over the long term in educational contexts. The limitations of the study included the cross-sectional design of the research, which precluded making causal inferences about the impact of body size perceptions on psychological health. Moreover, other aspects, such as the support of teachers and parents (Sánchez-Miguel et al., 2013), might be tested in order to enhance knowledge of the factors that promote PA.

In conclusion, our results suggest differences in the factors analyzed in the study (mainly levels of PA, body dissatisfaction and self-identity) between male and female adolescents. These findings support the promotion of IM in students with the aim of developing positive behaviors regarding PA in young students.

\section{References}

Altintas A, Asci FH, Kin-Isler A, Guven-Karahan B, Kelecek S, Ozkan A, Y1lmaz A, Kara FM. The role of physical activity, body mass index and maturity status in body related perceptions and self-esteem of adolescents. Ann Hum Biol, 2014; 41(5): 395-402. doi: 10.3109/03014460.2013.857721

Azevedo MR, Pavin CL, Fossati F, Vinholes F, Cozzensa M, Curi P. Gender differences in leisure - time physical activity. Int J Public Health, 2007; 52(1): 8-15. doi: 10.1007/s00038-006-5062-1

Biddle SJ, Pearson N, Ross GM, Braithwaite R. Tracking of sedentary behaviors of young people: a systematic review. Prev Med, 2010; 51(5): 345-351. http://dx.doi.org/10.1016/j.ypmed.2010.07.018 
Brener ND, McManus T, Galuska DA, Lowry R, Wechsler H. Reliability and validity of self-reported height and weight among high school students. J Adolesc Health, 2003; 32: 238-287. http://dx.doi.org/10.1016/S1054-139X(02)00708-5

Carson V, Staiano AE, Katzmarzyk PT. Physical activity, screen time, and sitting among U.S. adolescents. Pediatric Exerc Sci, 2015; 27(1): 151-159. http://dx.doi.org/10.1123\%2Fpes.2014-0022

Craig CL, Marshall AL, Sjöström M, Bauman AE, Booth ML, Ainsworth BE, Pratt M, Ekelund U, Yngve A, Sallis J, Oja P. International physical activity questionnaire: 12 country reliability and validity. Med Sci Sports Exerc, 2003; 35(8): 1381-1395. doi:10.1249/01.MSS.0000078924.61453.FB

Crawley H, Portides G. Self-reported versus measured height, weight and body mass index amongst 17-17 year old British teenagers. Int J Obes, 1995; 19: 579-584

Dagmar S, Erik S, Karel F, Aleš S. Gender Differences in Physical Activity, Sedentary Behavior and BMI in the Liberec Region: the IPAQ Study in 2002-2009. J Hum Kinet, 2011; 28: 123-131. doi:10.2478/v10078011-0029-6

Duncan DT, Wolin KY, Scharoun-Lee M, Ding EL, Warner ET, Bennet GG. Does perception equal reality? Weight misperception in relation to weight-related attitudes and behaviors among overweight and obese US adults. Int J of Behav Nutr Phys Activ, 2011; 22: 8-20. doi:10.1186/1479-5868-8-20

Finne E, Bucksch J, Lampert T, Kolip P. Age, puberty, body dissatisfaction, and physical activity decline in adolescents. Results of the German Health Interview and Examination Survey (KiGGS). Int J Behav Nutr Phys Act, 2011; 8: 19. doi:10.1186/1479-5868-8-119

Fox KR. The Physical Self-Perception Profile manual. DeKalb: Northern Illinois University, Office of Health Promotion; 1990

Fox KR, Corbin CD. The Physical Self-Perception Profile: Development and preliminary validation. J Sport Exercise Psychol, 1989; 11: 408-430

García-Hermoso A, Marina R. Relationship of weight status, physical activity and screen time with academic achievement in adolescents. Obes Res Clinic Pract, 2017; 11: 44-50. doi:10.1016/j.orcp.2015.07.006

Gillet N, Vallerand RJ, Lafrenière M-AK. Intrinsic and extrinsic school motivation as a function of age: the mediating role of autonomy support. Soc Psychol Edu, 2012; 15: 77-95. doi:10.1007/s11218-011-9170-2

González-Cutre D, Sicilia A, Fernández A. Toward a deeper understanding of motivation towards exercise: Measurement of integrated regulation in the Spanish context. Psicothema, 2010; 22(4): 841-847

Grogan S. Body Image: Understanding body dissatisfaction in men, women and children. London, UK, Routledge; 2008

Hair JF, Anderson RE, Tatham RL, Black WC. Multivariate Data Analysis (5th ed.). New Jersey, NJ, PrenticeHall; 1998

Janssen I, LeBlanc AG. Review systematic review of the health benefits of physical activity and fitness in school-aged children and youth. Int J Behav Nutr Phys Act, 2010; 7(40): 1-16. doi:10.1186/1479-5868-7-40

Lee IM, Shiroma EJ, Lobelo F, Puska P, Blair SN, Katzmarzyk PT, Lancet Physical Activity Series Working Group. Effect of physical inactivity on major non-communicable diseases worldwide: An analysis of burden of disease and life expectancy. Lancet, 2012; 380: 219-229. http://dx.doi.org/10.1016/S01406736(12)61031-9

Lowenthal KM. An introduction to psychological test and scales. 2nd Edition. UCLPress, London; 2001

Maszczyk A, Roczniok R, Waśkiewicz Z, Czuba M, Mikołajec K, Zajac A, Stanula A. Application of regression and neural models to predict competitive swimming performance. Percept Mot Skills, 2012; 114( 2): 610-626; doi: 10.2466/05.10.PMS.114.2.610-626

Moreno JA, Cervelló E, Vera JA, Ruiz LM. Physical self-concept of Spanish schoolchildren: Differences by gender, sport practice and levels of sport involvement. J Educ Hum Dev, 2007; 1: 1-17

Ntoumanis N. A self-determination approach to the understanding of motivation in physical education. British J Educ Psychol, 2001; 71: 225-242. doi:10.1348/000709901158497 
Rauner A, Mess F, Woll A. The relationship between physical activity, physical fitness and overweight in adolescents: a systematic review of studies published in or after 2000. BMC Pediatrics, 2013; 13: 19. doi:10.1186/1471-2431-13-19

Rodhes RE, Kaushal N, Quinlan A. Is physical activity a part of who I am? A review and meta-analysis of identity, schema and physical activity. Health Psychol Rev, 2016; 10(2): 204-225. doi: 10.1080/17437199.2016.1143334

Sánchez-Miguel PA, Leo FM, Sánchez-Oliva D, Amado D, García-Calvo T. The importance of parents' behavior in their children's enjoyment and amotivation in sports. J Hum Kinet, 2013; 36: 169-177. doi:10.2478/hukin-2013-0017

Strong WB, Malina RM, Blimkie CJ, Daniels SR, Dishman RK, Gutin B, Hergenroeder AC, Must A, Nixon PA, Pivarnik JM, Rowland T, Trost S, Trudeau F. Evidence based physical activity for school-age youth. J Pediatrics, 2005; 146(6): 732-737. http://dx.doi.org/10.1016/j.jpeds.2005.01.055

Stunkard AJ, Sorensen T, Schulsinger F. Use of the Danish Adoption Register for the study of obesity and thinnes. In: Kety S., Rowland L., Sidman R, Matthysse SW, eds. The Genetics of Neurological and Psychiatric Disorders. New York, NY: Raven Press, 115-120; 1983

Shen B. Outside-school physical activity participation and motivation in physical education. British J Edu Psychol, 2014; 84: 40-57. doi:10.1111/bjep.12004

Sylvia LG, Bernstein, EE, Hubbard, JL, Keating, L, Anderson, EJ. A practical guide to measuring physical activity. J Acad Nutr Diet, 2014; 114(2): 199-208. doi: 10.1016/j.jand.2013.09.018

Taliaferro LA, Rienzo BA, Donovan KA. Relationships between youth sport participation and selected health risk behaviors from 1999 to 2007. J Sch Health, 2010; 80: 399-410. doi: 10.1111/j.1746-1561.2010.00520.x

Teixeira PJ, Carraça EV, Markland D, Silva MN, Ryan RM. Exercise, physical activity, and self-determination theory: A systematic review. Int J Behav Nutr Phys Act, 2012; 9: 78. doi:10.1186/1479-5868-9-78

Teo EW, Khoo S, Wong R, Wee E-H, Lim BO, Rengasamy S. Intrinsic and extrinsic motivation among adolescent ten-pin bowlers in Kuala Lumpur, Malaysia. J Hum Kinet, 2015; 45: 241-251. doi:10.1515/hukin-2015-0025

Tessier S, Vuillemin A, Bertrais S, Boini S, Le Bihan E, Oppert JM, Hercberg S, Guillemin F, Briançon S. Association between leisure-time physical activity and health-related quality of life changes over time. Prev Med, 2007; 44(3): 202-208. doi:10.1515/hukin-2015-0025

Tremblay MS, LeBlanc AG, Janssen I, Kho ME, Hicks A, Murumets K, Colley RC, Duggan M. Canadian sedentary behaviour guidelines for children and youth. Appl Physiol Nutr Metab, 2011b; 36(1): 59-64. doi:10.1139/H11-012

Tremblay MS, LeBlanc AG, Kho ME, Saunders TJ, Larouch R, Colley RC, Goldfield G, Connor Gorber S. Systematic review of sedentary behaviour and health indicators in school-aged children and youth. Int J Behav Nutr Phys Act, 2011a; 8: 98. doi:10.1186/1479-5868-8-98

Van Mechelen W, Twisk JWR, Post GB, Snel J, Kemper HCG. Physical activity of young people: the Amsterdam longitudinal growth and health study. Med Sci Sports Exerc, 2000; 32(9): 1610-1616

Wilson PM, Rodgers WM, Loitz CC, Scime G. «It's who I am ... really!». The importance of integrated regulation in exercise contexts. J Appl Biobehav Res, 2006; 11(2): 79-104; doi: 10.1111/j.17519861.2006.tb00021.x

\section{Corresponding author:}

\section{Pedro Antonio Sánchez Miguel}

Teacher Training College, University of Extremadura

Avenida de la Universidad, S/N, 10003, Cáceres, Spain

Phone: +34927257647

E_mail: pesanchezm@unex.es 